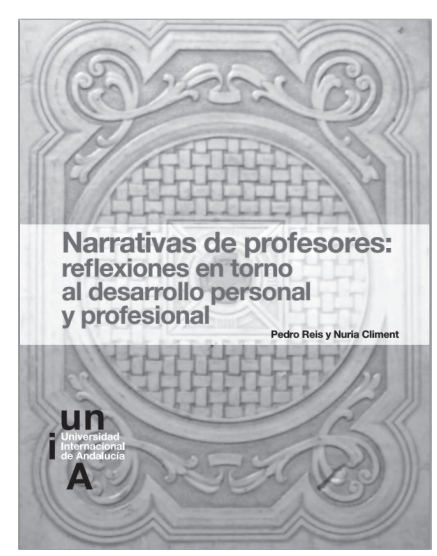

Reseña del libro

Narrativas de profesores:

reflexiones en torno al desarrollo personal y profesional

Fecha de recepción: 12 DE JUNIO DE 2015/Fecha de aceptación: 20 DE FEBRERO DE 2017/

Fecha de disponibilidad en línea: 16 DE MAYO DE 2017

Encuentre este artículo en http://magisinvestigacioneducacion.javeriana.edu.co/

Escrita por María Ángeles Hernández-Prados UnIVERSIDAD DE MURCIA MURCia, España mangeles@um.es

Este libro nace de la experiencia docente de los autores en el máster interuniversitario La investigación en la enseñanza y el aprendizaje de las ciencias experimentales, Sociales y Matemáticas, realizado en colaboración con las Universidades de Huelva, Extremadura e Internacional de Andalucía, que hace una apuesta decidida por la narrativa como recurso educativo que favorece la promoción del conocimiento mutuo y el desarrollo personal y profesional de docentes en distintas etapas de sus carreras.

Los autores destacan, en un capítulo introductorio, el potencial educativo e investigativo de las narrativas. La narrativa, en cualquiera de sus modalidades (narrativas de crítica social, de aprendizaje e inducción, de práctica reflexiva, de trayecto, de esperanza y deliberación), favorece pensamientos, orienta significados y propicia sin duda el desarrollo tanto personal, como profesional. Es una fuente de inspiración y conocimiento, que los estimula a reflexionar profundamente sobre sus ideas y los dilemas de su profesión. Pero también constituye un proceso de interacción, que integra la habilidad para escuchar y comprender las historias de las personas que viven a su alrededor.

Tras una cuidadosa selección de las narrativas, un total de 16, estas han sido agrupadas en seis secciones de acuerdo con sus temas predominantes. En la primera sección El profesor visto desde el alumno, se presentan dos modalidades de docentes que se mueven entre la sencillez

Para citar este artículo / To cite this article / Pour citer cet article / Para citar este artigo

Hernández-Prados, María Ángeles (2017). Reseña del libro. Narrativas de profesores: reflexiones en torno al desarrollo personal y profesional. magis, Revista Internacional de Investigación en Educación, 9 (19), 201-203. doi: 10.11144/Javeriana.m9-19.rlnp 
y la complejidad, la efectividad y la banalidad de su acción, o la sencillez efectiva y la complejidad banal, así como los efectos emocionales que estos promueven en los alumnos. El primer relato refleja un docente autoritario, disciplinado, metódico, que emplea la violencia, desde un grito, ridiculización o golpe con la regla, para favorecer el aprendizaje. En contraposición, el docente de la segunda historia se caracteriza por ser empático, ingenioso, motivador del aprendizaje, respetuoso con sus alumnos, aspectos todos ellos que favorecen una relación educativa cordial y responsable. Muchas de las vivencias escolares han sido borradas de nuestra memoria, pero sin lugar a dudas, han contribuido a hacer de nosotros lo que actualmente somos. Así lo exponen los autores "los maestros que el destino puso en cada una de sus vidas, han terminado por formarlos como personas adultas" (p. 43).

En lo que respecta a la formación de profesores, ambas narrativas reconocen la existencia de condicionamientos implícitos o explícitos, así como otras dimensiones subjetivas en la actuación del profesor, la necesidad de introducir mejoras e innovaciones en la formación del profesorado, la importancia de la didáctica específica y de que el conocimiento disciplinar es insuficiente para ser profesor de algo, como aspectos comunes. Además de esto, el primer relato nos permite reflexionar sobre la importancia de la autoevaluación docente, así como cuestionarse en qué medida se atienden las necesidades reales de sus alumnos (modelo ético) o la enseñanza está acomodada al docente (modelo didáctico), mientras que la segunda historia se centra en la inducción en sus alumnos de nuevas formas de concebir la enseñanza, la relevancia de la formación permanente y la reflexión sobre la praxis docente.

La primera narrativa del tercer bloque que lleva por título Ser profesor, se sitúa en los años 70, una época marcada por momentos sociopolíticos y por la fuerte convicción de que la educación es vía de movilidad social. En este sentido, profundiza en la necesidad de conectar los contenidos curriculares con el compromiso social, la importancia de organización y liderazgo de la institución educativa, para promover la participación en proyectos de paz, multiculturalismo... Por su parte, la segunda experiencia se centra en la capacidad de adaptación y reciclaje docente, tanto para el cambio de los contenidos curriculares adaptados a las motivaciones de los alumnos, así como para favorecer la participación de personas ajenas al centro y las alianzas entre la Universidad y Escuela. Por último, se expone un modelo de ser docente desde una visión abierta de la educación como algo innato y natural, según la cual enseñamos y aprendemos a la vez, y se critica al hecho de que prevalezcan más los conceptos de las asignaturas que las propias actitudes del alumnado.

Los inicios en la labor docente han sido plasmados por medio de dos narrativas recogidas bajo el título Primeros pasos de la enseñanza. Repetir la educación que recibí, tomar conciencia de las necesidades del otro, descubrimiento y reconocimiento del otro, y actuar, son las cuatro etapas por las que atravesó el primer docente en sus inicios. De igual modo, para el segundo docente, la individualidad de los alumnos es esencial en la evaluación, así como el conocimiento de las posibilidades educativas que le brindan otros contextos. En ambos casos, se trata de recuperar el protagonismo del alumno en la acción educativa.

El apartado Diferenciación pedagógica es el que más narrativas aglutina, cuatro, y aborda aspectos esenciales de la educación escolar: cómo promover la motivación hacia las matemáticas desde la papiroflexia, la magia y pruebas de ingenio; cómo afrontar las conductas disruptivas de los alumnos desde un programa de modificación de conductas; cómo educar 
desde el entusiasmo y la vocación profesional para promover la capacidad de trabajar, el esfuerzo y la disciplina; cómo detectar el nivel de conocimientos por medio de los debates; cómo conseguir implicar al alumnos en su propio aprendizaje.

El último bloque, titulado La escuela como cambio, está compuesto por tres narrativas. La primera de ellas se centra en un proyecto de capacitación de alumnos con la finalidad de motivarlos hacia las actividades académicas esenciales, como escribir y leer, recurriendo a estrategias pedagógicas diferenciadas y adaptadas a los distintos ritmos y estilos de aprendizaje (juego y trabajo cooperativo), así como a la pedagogía del afecto y la ternura. La segunda narrativa trata la experiencia en una escuela de primaria cuyo propósito era sembrar ilusiones en los hijos de obreros y de pequeños obreros, para formar ciudadanos responsables que supieran vivir en libertar y cuidar esa libertad, en especial porque no hacía mucho se había librado de la opresión de un gobierno totalitario. La última narrativa trata sobre el trabajo cooperativo entre profesores y alumnos, para reflexionar juntamente sobre el problema de desigualdad en el mundo. Se trata de promover el sentimiento solidario, de crear una plataforma de justicia tanto en alumnos como docentes.

\section{Sobre la autora}

María Ángeles Hernández-Prados es licenciada y doctora en pedagogía, Premio Nacional Fin de Carrera, profesora contratada doctora en el departamento de Teoría e Historia de la Educación, Universidad de Murcia. Imparte docencia en teoría de la educación y materias relacionadas con la educación familiar. Su producción científica se relaciona con las siguientes líneas de investigación: educación para la ciudadanía y mejora de la convivencia escolar (formación del profesorado, escuelas de padres, etc.), educación en valores en el contexto familiar (resolución de conflictos, aprendizaje de normas, implicación parental en las cuestiones escolares, educar en y desde la responsabilidad, etc.), perspectiva ético-moral de la sociedad de la información (la seguridad de los menores en la red, ciudadanía digital, cyberbullying, etc.).
Descripción del artículo | Article description | Description de l'article | Artigo descrição

Reseña basada en el libro de Pedro Reis \& Nuria Climent (2012). Narrativas de profesores: reflexiones en torno al desarrollo personal y profesional. Sevilla, Universidad Internacional de Andalucía, UNIA. 208 páginas. ISBN: 978-84-7993-235-0 